\title{
MODIFIKASI DAN UJI KINERJA UNIT PENYOSOH PADA MESIN PENYOSOH BIJI HANJELI (MPBH-0219)
}

\section{MODIFICATION AND PERFORMANCE TESTING OF POLISHING UNIT ON HANJELI POLISHING MACHINE (MPBH-0219)}

\author{
Wahyu K Sugandi ${ }^{1 凶}$, Ruminta $^{2}$, Asep Yusuf ${ }^{1}$, Theresia Romey ${ }^{1}$ \\ ${ }^{1}$ Departemen Teknik Pertanian dan Biosistem, Fakultas Teknologi Industri Pertanian, Universitas Padjadjaran \\ ${ }^{2}$ Departemen Budidaya Pertanian, Fakultas Pertanian, Universitas Padjadjaran \\ ${ }^{\otimes}$ Komunikasi Penulis, email: sugandiwahyu@gmail.com \\ DOI:http://dx.doi.org/10.23960/jtep-lv9i2.71-77
}

Naskah ini diterima pada 31 Januari 2020; revisi pada 20 Maret 2020;

disetujui untuk dipublikasikan pada 30 Maret 2020

\begin{abstract}
Hanjeli has a hard rind, so it takes a peeler and polisher to process it. One of the machines used is the Hanjeli Polishing Machine AGR-RM40 in the Faculty of Agriculture, Padjadjaran University. However, this machine has the disadvantage that most of the hanjeli seeds are crushed and are not polished. This is due to the polishing space which is quite narrow so that it puts great pressure on the hanjeli seeds during the polishing. Meanwhile, the existence of unpolished hanjeli was caused by poor friction between the cylinders and hanjeli. Therefore, this machine needs to be modified to improve the results of a better polishing. The method used in this research was engineering with several stages, such as designing a polishing unit, analysis, and performance testing on hanjeli batu and hanjeli pulut. The modification of the Polishing Unit on Hanjeli Polishing Machine (MPBH-0219) has a cylinder length dimension of $167 \mathrm{~mm}$ and a diameter of $37.9 \mathrm{~mm}$. Based on the performance test, this machine is good and worth using where actual capacity is obtained $35 \mathrm{~kg} / \mathrm{hour}, 96 \%$ engine efficiency, 58,46\% dumping yield, 0.50 performance, and $1.30 \mathrm{~kW}$ actual power requirements.
\end{abstract}

Keywords: hanjeli, modification, polishing machine, performance test

\begin{abstract}
ABSTRAK
Hanjeli memiliki kulit yang keras sehingga dibutuhkan mesin pengupas dan penyosoh untuk mengolahnya. Salah satu mesin yang digunakan adalah Mesin Penyosoh Biji Hanjeli AGR-RM40 yang terdapat di Fakultas Pertanian, Universitas Padjadjaran. Namun, mesin ini memiliki kelemahan yaitu biji hanjeli hasil penyosohan sebagian besar pecah dan tidak tersosoh. Pecahnya biji hanjeli diakibatkan oleh ruang penyosoh yang cukup sempit sehingga memberi tekanan yang besar pada biji hanjeli saat terjadi penyosohan. Sementara itu, adanya hanjeli yang tidak tersosoh diakibatkan oleh gesekan antara silinder penyosoh dan hanjeli belum maksimal. Oleh karena itu, mesin ini perlu dimodifikasi agar meningkatkan hasil penyosohan yang lebih baik. Metode yang digunakan pada penelitian ini adalah rekayasa dengan beberapa tahapan, seperti perancangan ruangan penyosoh, analisis, serta uji kinerja pada hanjeli batu dan hanjeli pulut Hasil modifikasi ruang penyosoh Mesin Penyosoh Biji Hanjeli (MPBH-0219) memiliki dimensi panjang silinder $167 \mathrm{~mm}$ dan diameter 37,9 mm. Berdasarkan uji kinerja mesin ini cukup baik dan layak digunakan di mana diperoleh kapasitas aktual $35 \mathrm{~kg} / \mathrm{jam}$, efisiensi mesin $96 \%$, rendemen penyosohan $58,46 \%$, performansi 0,50 , dan kebutuhan daya aktual $1,30 \mathrm{~kW}$.
\end{abstract}

Kata Kunci: biji hanjeli, mesin penyosoh, modifikasi, uji kinerja

\section{PENDAHULUAN}

Hanjeli (Coix lacryma-jobi L.) merupakan bahan pangan yang memiliki banyak kandungan gizi sehingga dapat dimanfaatkan. Pengolahan pasca panen hanjeli dapat dilakukan apabila telah disosoh. Selama ini banyak penyosohan biji hanjeli mengahsilkan biji yang pecah padahal konsumen menginginkan biji hanjeli yang tidak pecah sehingga diperlukan mesin khusus untuk menyosoh biji hanjeli. Masalah lain dari biji hanjeli adalah kulitnya keras sehingga sangat 
sulit dikupas tanpa menggunakan mesin penyosoh.

Mesin Penyosoh Biji Hanjeli (MPBH-0219) yang berada di Laboratorium Teknologi Produksi Tanaman Fakultas Pertanian Universitas Padjadjaran merupakan salah satu mesin penyosoh biji hanjeli yang sudah dioperasikan. Mesin ini merupakan hasil modifikasi Mesin Penyosoh Biji Hanjeli AGR-RM40. Mesin ini berfungsi dengan cukup baik namun masih terdapat beberapa kelemahan pada mesin penyosoh biji hanjeli (MPBH-0219), diantaranya: 1) jumlah hanjeli tersosoh utuh yang dihasilkan sedikit, yaitu $26,71 \%$ untuk hanjeli batu dan 34,08\% untuk hanjeli pulut diakibatkan oleh sempitnya ruang antara silinder dan saringan penyosoh sehingga hanjeli lebih banyak yang pecah saat dilakukan penyosohan dan 2) jumlah biji yang belum tersosoh dan terkupas sebesar $10 \%$ untuk hanjeli batu dan $4,48 \%$ untuk hanjeli pulut sedangkan jumlah biji tersosoh sebagian sebesar $4,56 \%$ untuk hanjeli batu dan 3,19\% untuk hanjeli pulut.

Berdasarkan permasalahan di atas perlu dilakukan modifikasi unit penyosoh pada Mesin Penyosoh Biji Hanjeli (MPBH-0219) sehingga diharapkan mesin hasil modifikasi dapat bekerja dengan baik dan menghasilkan hanjeli yang utuh dan tersosoh dengan baik.

\section{BAHAN DAN METODA}

Peralatan yang digunakan untuk memodifikasi alat ini yaitu mesin bubut, gerinda tangan, kikir, ragum, kunci ring dan amplas. Sedangkan peralatan pengujian mesin penyosoh hanjeli yaitu clamp on meter, jangka sorong, stopwatch, timbangan analitik dan sound level meter, Tachometer digital sedangkan untuk mendesain hasil rancangan gambar teknik menggunakan Software Autocad.

Bahan baku yang digunakan pada penelitian ini yaitu hanjeli batu dan hanjeli pulut. Metode penelitian yang digunakan adalah metode rekayasa (engineering). Metode rekayasa merupakan suatu kegiatan perancangan (design) yang tidak rutin sehingga menghasilkan suatu kontribusi dalam bentuk proses maupun produk (Herwanto,1983). Secara rinci tahapan pada Gambar 1.

\section{1) Identifikasi masalah}

Identifikasi dilakukan untuk mengetahui masalah yang terdapat pada mesin penyosoh biji hanjeli MPBH-0219 sehingga dapat dijadikan sebagai dasar untuk melakukan modifikasi dan perbaikan.

\section{2) Penentuan kriteria mesin yang dimodifikasi}

Berdasarkan pengamatan langsung di lapangan maka hal yang menjadi dasar perancangan adalah memperkecil silinder penyosoh dengan mengurangi diameter silinder untuk memperbesar volume ruang penyosohan. Semakin besar diameter silinder penyosohan maka hanjeli yang pecah akan berkurang sedangkan hanjeli yang utuh akan meningkat.

\section{3) Perancangan}

Perancangan yang digunakan pada penelitian ini meliputi: rancangan fungsional dan rancangan struktural. Rancangan fungsional dilakukan untuk menentukan fungsi komponenkomponen penyusun mesin penyosoh biji hanjeli (MPBH-0219). Rancangan struktural diperlukan untuk menentukan bentuk, ukuran, dan tata letak dari setiap komponen fungsional dan struktur mesin secara keseluruhan.

\section{4) Pembuatan gambar teknik}

Pembuatan gambar mesin dilakukan berdasarkan analisis perancangan fungsional dan perancangan struktural. Gambar desain disesuaikan dengan dimensi dan ukuran setiap komponen yang ada pada mesin. Pembuatan gambar mesin dilakukan menggunakan software AutoCad.

\section{5) Melakukan modifikasi}

Modifikasi dilakukan pada komponenkomponen mesin sesuai dengan hasil gambar teknik dan perancangan yang telah dilakukan sebelumnya. Jadi, tahap ini merupakan tahap untuk merealisasikan secara fisik hasil rancangan.

\section{6) Pengujian Mesin}

Pengujian yang dilakukan adalah uji fungsional dan uji kinerja. Uji fungsional merupakan 
pengujian yang dilakukan untuk mengetahui kesesuaian fungsi setiap komponen mesin dengan kriteria perancangan. Uji kinerja dilakukan untuk mengetahui kesesuaian kinerja mesin yang telah dimodifikasi dengan kriteria perancangan. Parameter yang diuji pada uji kinerja adalah: kapasitas teoritis, kapasitas aktual, efisiensi, rendemen penyosohan, indeks performansi, tingkat getaran, dan tingkat kebisingan.

Kapasitas teoritis penyosohan ini mengacu pada perhitungan kapasitas teoritis sistem batch Mesin Penyosoh Biji Hanjeli oleh Sari (2019). Perhitungan kapasitas teoritis dapat dilihat pada Persamaan 1.

$$
K t=\frac{\rho * \pi * l *\left(r_{0}^{2}-r_{1}^{2}\right) * 60}{t}
$$

Dimana, Kt adalah kapasitas teoritis mesin $(\mathrm{kg} /$ jam), $\rho$ adalah densitas biji hanjeli $\left(\mathrm{kg} / \mathrm{m}^{3}\right), \mathrm{r}_{1}$ adalah jari-jari silinder sosoh (m), $r_{0}$ adalah jarijari saringan $(\mathrm{m}), \mathrm{l}$ adalah panjang ruang penyosohan (m), dan t adalah waktu penyosohan (menit).
Perhitungan kapasitas aktual penyosohan dapat diperoleh dengan Persamaan 2 (SNI 0835:2008)

$$
K a=M k \frac{60}{t k}
$$

Dimana, Ka adalah kapasitas aktual mesin penyosoh $(\mathrm{kg} / \mathrm{jam}), \mathrm{Mk}$ adalah berat hanjeli sosoh yang keluar dari mesin (kg), dan tk adalah waktu yang dibutuhkan untuk penyosohan (menit).

Efisiensi penyosohan dapat dihitung dengan menggunakan Persamaan 3 (Itasari, 2017):

$$
E f=\frac{K a}{K t} * 100 \%
$$

Dimana, Ef adalah efisiensi mesin (\%).

Rendemen penyosohan dapat dihitung dengan menggunakan Persamaan 4 (SNI 0835:2008):

$$
R=\frac{M L K}{M L M} * 100 \%
$$

Dimana, R adalah rendemen biji hanjeli tersosoh (\%), MLK adalah massa biji hanjeli yang tersosoh

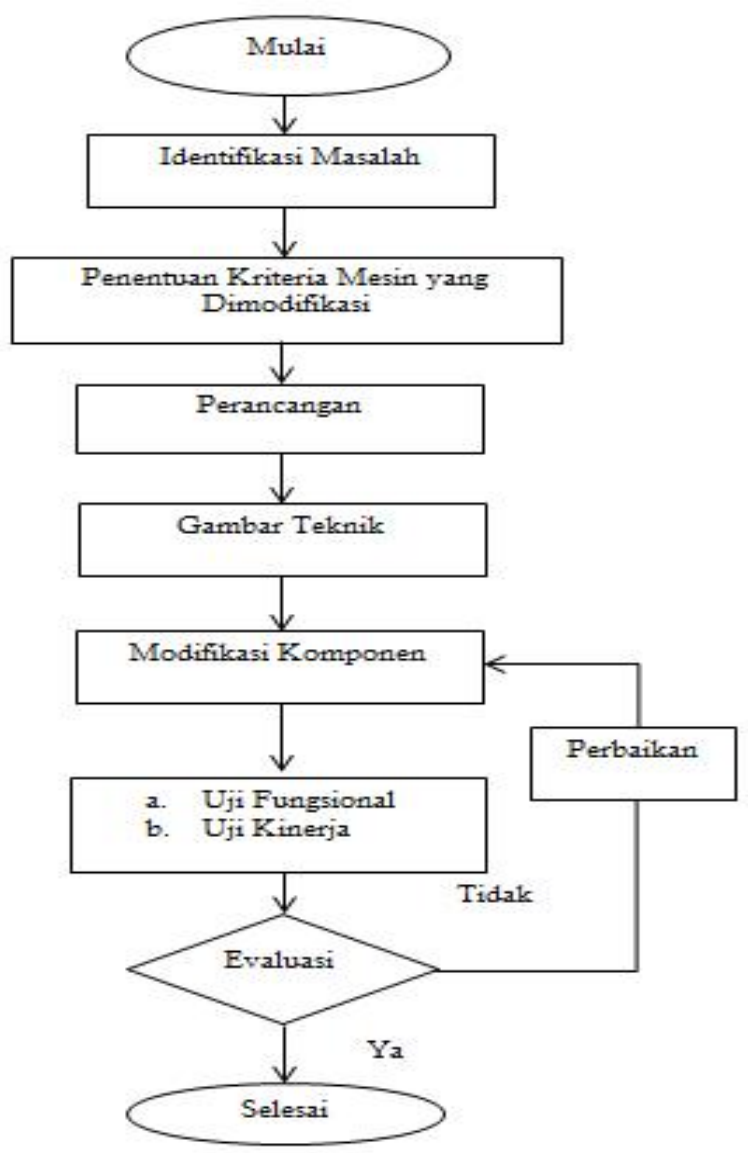

Gambar 1. Diagram Alir Penelitian 
(kg), dan MLM adalah massa biji hanjeli yang dimasukkan ke dalam hopper (kg).

Indeks performansi merupakan angka yang menunjukkan besarnya nilai kerja unit suatu mesin. Besarnya nilai indeks performansi berkisar 0-1 dan apabila nilainya semakin mendekati satu maka semakin bagus. Indeks performansi untuk mesin penyosoh dapat dihitung dengan menggunakan Persamaan 5:

$$
I p=\frac{M a * X a+M b * X b+M c * X c}{M a+M b+M c}
$$

Dimana, Ma adalah massa hanjeli tersosoh utuh (kg), Mb adalah massa hanjeli tersosoh pecah (kg), Mc adalah massa hanjeli tidak tersosoh dan tersosoh sebagian (kg), Xa adalah fraksi hanjeli tersosoh utuh (kg), Xb adalah fraksi hanjeli tersosoh pecah (kg), dan Xc adalah fraksi hanjeli tidak tersosoh dan tersosoh sebagian $(\mathrm{kg})$.

Tujuan perhitungan energi spesifik penyosohan hanjeli adalah untuk mengetahui besaran energi yang diperlukan untuk menyosoh bahan setiap kg. Perhitungan energi spesifik dihitung dengan Persamaan 6 sebagai berikut:

$$
E_{s p}=\frac{P_{a p} * 3600}{K_{a p}}
$$

Dimana, $\mathrm{E}_{\mathrm{sp}}$ adalah energi spesifik (J/kg), P adalah Daya motor (W), dan Ka adalah kapasitas aktual $(\mathrm{kg} / \mathrm{jam})$.

\section{HASIL DAN PEMBAHASAN}

\subsection{Kriteria Perancangan}

Mesin yang akan dimodifikasi diharapkan memiliki kriteria sebagai berikut:

1) Biji hanjeli yang tersosoh utuh sebesar $35 \%$ untuk hanjeli batu dan $45 \%$ untuk hanjeli pulut.

2) Jumlah hanjeli yang belum tersosoh dan terkupas paling banyak sebesar 5\% untuk hanjeli batu dan hanjeli pulut sedangkan jumlah hanjeli tersosoh sebagian paling banyak 2\% untuk hanjeli batu dan hanjeli pulut.

\subsection{Mesin Hasil Modifikasi}

Modifikasi dilakukan pada bagian unit penyosoh mesin tersebut, yaitu pada silinder penyosoh. Mesin utuh sebelum dimodifikasi dapat dilihat pada Gambar 2 dan bagian yang dimodifikasi dapat dilihat pada Gambar 3.

Diameter silinder penyosoh dikurangi sebesar $1 \mathrm{~mm}$ untuk memperbesar ruang penyosohan sehingga output juga akan semakin besar. Diameter awal silinder penyosoh adalah 38,9 $\mathrm{mm}$ dan diameter setelah dimodifikasi adalah $37,8 \mathrm{~mm}$.

\subsection{Kapasitas Teoritis}

Kapasitas teoritis berdasarkan hasil perhitungan adalah $39 \mathrm{~kg} / \mathrm{jam}$ untuk hanjeli batu dan $50 \mathrm{~kg} /$ jam untuk hanjeli pulut. Besarnya kapasitas teoritis dipengaruhi oleh kerapatan kamba (bulk

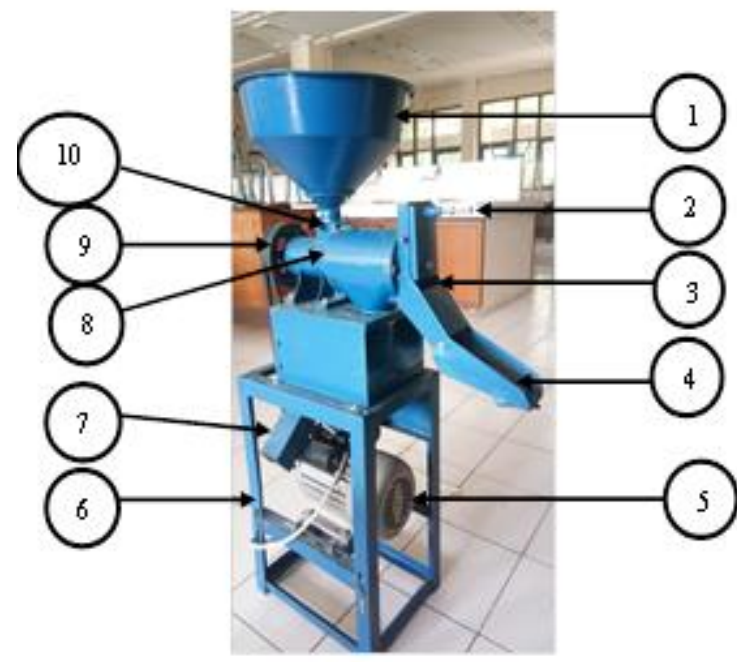

Dimanx:

1. Hopper

2. Pengatux penyosohan hanj eli

3. Pintu outpar ruang penyosoh

4. Saluran oatpar

5. Motor listrik

6. Ranglad

7. Ruang output selam

8. Silinder luaran perryosoh

9. Sabuk transmisi

10. Pengatux pemasukan biji

Gambar 2. Mesin Penyosoh Hanjeli 
density) biji hanjeli, volume ruang penyosoh, dan waktu yang diperlukan untuk penyosohan. Waktu yang digunakan untuk melakukan penyosohan hanjeli batu lebih lama dibandingkan waktu untuk hanjeli pulut sehingga menyebabkan kapasitas teoritis hanjeli batu lebih kecil. Lamanya waktu penyosohan ini diakibatkan oleh kulit hanjeli batu yang lebih keras dan lebih tebal.

\subsection{Kapasitas Aktual}

Kapasitas aktual hasil pengukuran adalah $35 \mathrm{~kg} /$ jam untuk hanjeli batu dan $48 \mathrm{~kg} / \mathrm{jam}$ untuk hanjeli pulut. Kapasitas aktual dipengaruhi oleh waktu dan karakteristik fisik bahan. Karakteristik bahan yang mempengaruhi adalah tingkat kekerasan. Hubungan kapasitas aktual dan tingkat kekerasan berbanding lurus di mana semakin keras sifat suatu bahan maka akan dibutuhkan waktu yang lebih lama untuk melakukan penyosohan. Hanjeli batu memiliki kulit yang lebih keras dan tebal dibandingkan hanjeli pulut sehingga waktu penyosohannya semakin lama.

\subsection{Efisiensi Penyosohan}

Berdasarkan Persamaan 3, efisiensi penyosohan hanjeli batu adalah sebesar $89,74 \%$ sedangkan hanjeli pulut adalah 96\%. Efisiensi mesin dipengaruhi oleh kapasitas aktual mesin di mana semakin besar kapasitas aktual maka akan semakin tinggi nilai efisiensi mesin.

\subsection{Rendemen Penyosohan}

Berdasarkan hasil perhitungan pada Persamaan 4, rendemen penyosohan hanjeli batu adalah $50,07 \%$ sedangkan hanjeli pulut memiliki rendemen 58,46\% (Gambar 4 a dan b). Hanjeli yang keluar dari ruang penyosohan tidak semuanya utuh melainkan ada yang pecah dan tidak tersosoh sempurna. Adapun hasil dari penyosohan hanjeli batu dan pulut seperti yang disajikan pada Tabel 1 .

\subsection{Kebutuhan Daya Aktual}

Berdasarkan hasil pengukuran dengan menggunakan menggunakan clamp meter untuk penyosohan pada hanjeli batu adalah $1,67 \mathrm{~kW}$ dan untuk hanjeli pulut sebesar 1,30 kW.
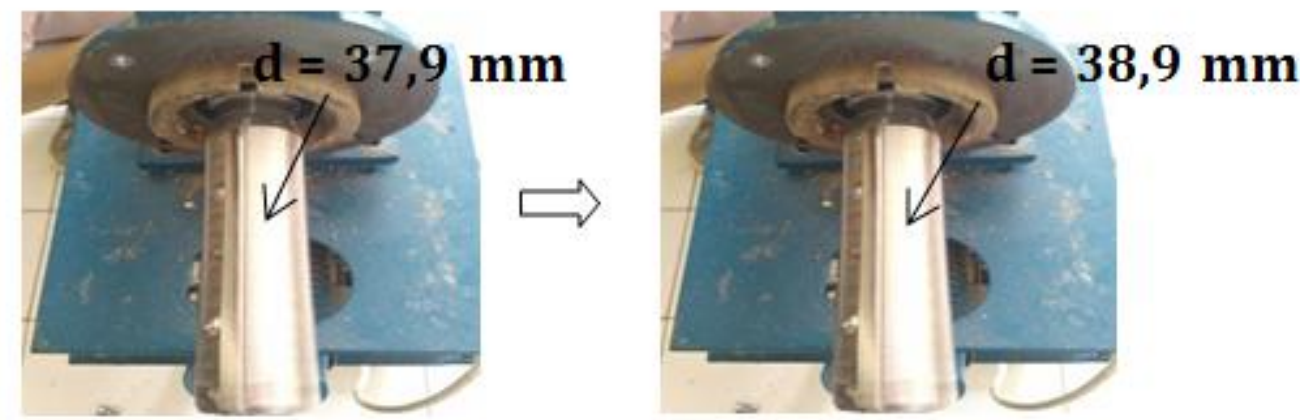

Gambar 3. Silinder Penyosoh Setelah Dimodifikasi

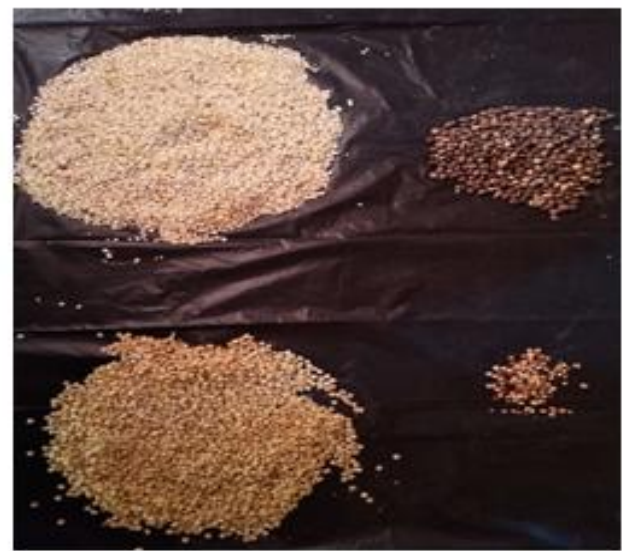

(a)

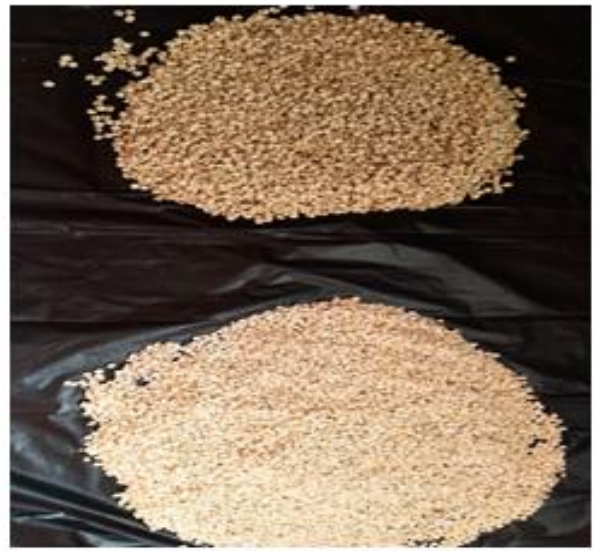

(b)

Gambar 4. Hasil Penyosohan (a) Hanjeli Batu dan (b) Hanjeli Pulut 
Tabel 1. Persentasi Hasil Penyosohan Mesin Penyosoh Biji Hanjeli MPBH-0219 pada Varietas Batu dan Varietas Pulut

\begin{tabular}{llcc}
\hline No & Persentasi Hasil Penyosohan (\%) & Varietas Batu & Varietas Pulut \\
\hline 1. & Biji Hanjeli Tersosoh Utuh & 20,33 & 27,67 \\
2. & Biji Hanjeli Tersosoh Pecah & 29,74 & 30,79 \\
3. & Biji Hanjeli Tersosoh Sebagian & 0,56 & 0,12 \\
4. & Biji Hanjeli Tidak Tersosoh dan Tidak Terkupas & 2,91 & 0 \\
\hline
\end{tabular}

\subsection{Energi Spesifik Penyosohan}

Energi spesifik penyosohan dapat dihitung berdasarkan data kapasitas aktual mesin dan daya aktual penyosohan. energi spesifik penyosohan pada hanjeli batu adalah sebesar $172,49 \mathrm{~kJ} / \mathrm{kg}$ sedangkan pada hanjeli pulut sebesar 95,58 kJ/kg. Karakteristik fisik masingmasing bahan dapat mempengaruhi nilai kapasitas aktual dan daya aktual mesin di mana kapasitas dan daya aktual akan berpengaruh terhadap besarnya energi spesifik penyosohan. Semakin besar daya aktual penyosohan maka akan semakin besar juga energi spesifik yang dihasilkan sedangkan jika semakin besar kapasitas aktual maka energi spesifik akan semakin kecil.

\subsection{Indeks Performansi}

Indeks merupakan nilai yang menunjukkan fungsi kerja suatu mesin. Nilai indeks performansi berkisar antara 0-1 dan apabila nilainya semakin mendekati satu maka semakin baik. Nilai indeks performansi penyosohan MPBH-0219 berada di bawah nilai 1, yaitu 0,53 untuk hanjeli batu dan 0,50 untuk hanjeli pulut. Hal yang mempengaruhi besarnya nilai yang diperoleh adalah hasil penyosohan hanjeli. Hanjeli tidak semuanya tersosoh sempurna, masih terdapat hanjeli yang tersosoh sebagian, tidak tersosoh, dan tidak terkupas. Hasil penyosohan hanjeli beragam karena dipengaruhi oleh karakteristik bahan seperti kekerasan bahan dan kerapatan kamba (bulk density). Hanjeli batu memiliki kulit yang lebih keras dan susah disosoh dibandingkan hanjeli pulut sehingga menyebabkan lebih banyak biji hanjeli batu yang pecah, tidak tersosoh, dan tidak terkupas.

\subsection{Kebisingan}

Berdasarkan hasil pengukuran dengan menggunakan soundlevel meter, Rata-rata nilai kebisingan untuk hanjeli batu adalah 84,288 dB sedangkan untuk hanjeli pulut adalah 83,732 dB. Kebisingan yang dihasilkan pada hanjeli batu lebih besar daripada hanjeli pulut. Hal ini diakibatkan oleh kulit hanjeli batu yang lebih keras dan lebih tebal daripada kulit hanjeli pulut. Tingkat kebisingan maksimal yang diizinkan berdasarkan SNI 0835-2008 adalah sebesar 90 dB sedangkan berdasarkan Keputusan Menteri Tenaga Kerja Nomor 51 tahun 1999 tingkat kebisingan maksimal adalah $85 \mathrm{~dB}$ sehingga dapat disimpulkan bahwa tingkat kebisingan mesin penyosoh hanjeli hasil modifikasi masih di batas normal.

\section{KESIMPULAN}

Adapun kesimpulan dari penelitian ini adalah sebagai berikut hasil Modifikasi Mesin Penyosoh Biji Hanjeli terutama pengurangan pada diameter silinder penyosoh sebesar $1 \mathrm{~mm}$. Kapasitas aktual mesin penyosoh hanjeli untuk biji hanjeli batu adalah $35 \mathrm{~kg} / \mathrm{jam}$ dan biji hanjeli pulut adalah 48 $\mathrm{kg} / \mathrm{jam}$. Efesiensi mesin penyosoh hanjeli untuk biji hanjeli batu adalah 89,74\% dan biji hanjeli pulut adalah $96 \%$. Rendemen penyosoh hanjeli untuk biji hanjeli batu adalah 50,07 \% dan biji hanjeli pulut adalah 58,46 \%. Nilai daya aktual untuk penyosoh hanjeli untuk biji hanjeli batu adalah $1,67 \mathrm{~kW}$ dan biji hanjeli pulut adalah 1,30 $\mathrm{kW}$. Nilai indeks performansi untuk penyosoh hanjeli untuk biji hanjeli batu adalah 0,53 dan biji hanjeli pulut adalah 0,50 . Tingkat kebisingan untuk mesin penyosoh hanjeli adalah $83-84 \mathrm{~dB}$.

\section{DAFTAR PUSTAKA}

Badan Standar Nasional Indonesia. SNI 0835:2008. Mesin Penyosoh Beras, Unjuk Kerja dan Cara Uji. 
Herwanto, T., S.Nurjanah., D.Rusendi., T. Pujianto., R.Kastaman. 1983. Modul Integrasi Bahan Ajar (IBA). Faperta, Unpad. Bandung.

Itasari, Ira. 2017. Uji Kinerja dan Analisis Ekonomi Mesin Penyosoh Hanjeli TEP-04. Skripsi. Fakultas Teknologi Industri Pertanian. Unpad. Jatinangor.
Menteri Tenaga Kerja Republik Indonesia. 1999. (KEPMENAKER N0. Kep-51/Men/1999). Nilai Ambang Batas Faktor Fisika di Tempat Kerja. Jakarta.

Sari, I. R. 2019. Uji Kinerja Dan Analisis Ekonomi Mesin Penyosoh Biji Hanjeli (Coix Lacyma-Jobi L.) AGR-RM40. Skripsi. Fakultas Teknologi Industri Pertanian. Universitas Padjadjaran. Jatinangor. 